\title{
Traumatized Children and Post-Traumatic Growth in Francophone Trauma Novels
}

\author{
SUZANNE LALONDE, PhD, University of Texas Rio Grande Valley \\ Corresponding author: Suzanne LaLonde \\ suzlalonde@gmail.com
}

\begin{abstract}
In an attempt to decolonize Trauma Studies, a dominant mental health discourse, and to expand our understanding of trauma and post-traumatic growth, this project investigates J.M.G. Le Clézio's The African (L'africain 2004) and Ahmadou Kourouma's: Allah is Not Obliged 2011) (Allah n'est pas obligé 2000) and the untranslated and unfinished Quand on refuse on dit non (2004). The term "decolonizing Trauma Studies" refers to a remapping of this particular field of Cultural Theory by studying these non-Western "trauma novels". The first critical suggestion advanced is that these authors explore the traumatic consequences of lies that are ontological and phenomenological in nature and maintained through language (logos). This research then examines Le Clézio's and Kourouma's models of healing, which centre on the body, language, and an empathetic re-encounter with the traumatized self through narratives. Another major finding is that these texts experiment with literature, manipulating it into new forms, thus expanding our understanding of the relationship between the literary arts and posttraumatic growth theories and treatments.
\end{abstract}

Keywords: Trauma Studies; trauma; post-traumatic growth; trauma novel; decolonization

\section{Moving beyond Western concepts of trauma and growth}

Culture today is "saturated with trauma" whether on an individual, collective, political, medical, or environmental level (Luckhurst, 2013, p. 2). Consequently, "the study of trauma is clearly on the current agenda of many scholars, especially in the field of literary studies" (LaCapra, 2014, p. ix).

Indeed, since the 1990s, trauma theories have impacted Cultural Studies, while a new literary genre "the trauma novel" has been named and developed. Some trauma theorists have argued that in a "catastrophic age" such as ours, "trauma itself may provide the very link between cultures" (Caruth, 1995, p. 56). If Gilles Deleuze has argued that literature is an enterprise of health because it invents a people who are missing (1999, p. 11-14), one can imagine that the literary arts and especially the "trauma novel" may have a therapeutic role to play in post-traumatic theories and treatments. It could invent a survivor of 
trauma who knows a certain degree of healing as opposed to a victim who continues to dwell in a traumatic experience. Deleuze's faith in the therapeutic role of literature finds resonance in the research of cultural theorist Cathy Caruth, who claims that the transmission of a traumatic experience must "be spoken in a language that is always somehow literary: a language that defies, even as it claims, our understanding” (1995, p. 5).

However, does it really make sense to imagine that the literary arts can promote post-traumatic growth and resilience? Does post-traumatic recovery just boil down to traumatic experiences translated into a literary language? Besides, how does one define a literary language? More fundamentally, how can the literary arts promote growth and resilience if "the story of the traumatic event surfaces not as a verbal narrative but as a symptom" (Herman, 1992, p. 1)? Furthermore, how can the literary imagination possibly help to heal survivors, if "trauma has shut down their inner compass and robbed them of the imagination they need to create something better" (van der Kolk, 2014, p.8)? These questionsbuttressed by the research of clinicians Judith Herman and Bessel van der Kolk-underscore the limitations of the literary arts, intimating that the field is incompatible on a fundamental level with posttraumatic growth therapies, considering that the story of trauma is not verbal and that post-traumatic experiences are defined by an impoverished imagination.

The issue of an intrinsic incompatibility between the literary arts and post-traumatic growth theories and practices is exacerbated by several idiosyncrasies within Trauma Studies. Many cultural theorists have called for a decolonization of the field, arguing that it is dominated by hegemonic health discourses from the West. Critics also complain that it focuses too much on trauma, as opposed to modes of growth. "By putting trauma at the center of a theory of representation," write post-colonist theorists Ewald Mengel and Michela Borzaga, "their melancholic vocabulary is one marked by notions of absence, holes, deferral, crises of meaning and dissociation" (2012, p. xiii). They conclude that the 
field has a tendency to "neglect the agency, resistance, resilience and creativity of people in times of trauma" (2012, p. xiv). This reading is quite arresting and brings to mind what psychiatrist Arthur Kleinman wrote in reference to medical care: "Cultural issues are allowed to slip by, one after another in a way that would be regarded as sheer clinical incompetence if the issues were biological” (1988, p. $135)$.

In an attempt to address these problematic traits of Trauma Studies and the apparent incompatibility between the literary arts and post-traumatic growth therapies, this project focuses on non-Western trauma novels. If the Martiniquais philosopher and psychiatrist Frantz Fanon claimed that decolonization simply meant the replacing of a certain species of men by another species of men (1963, p.1), we are suggesting not so much a replacement of theories and practices, but rather an embellishment. Fanon also predicted that decolonization was going to be a violent event (1963, p. 1), whereas the South African author Mothobi Mutloatse warned that, “...we are going to kick and pull and push and drag literature into the form we prefer..." (2001, p. 5). There has been in fact a "decolonization" of the novel, such that post-colonial trauma novels are beginning to enrich our understanding of trauma, growth, and even literature itself (See Craps (2013), Craps and Buelens (2008), Mengel and Borzaga (2012), Michael Rothberg (2008), and Mutloatse (1981).) While most of the research on these topics focuses on texts written in English, this article investigates Francophone postcolonial literature. It studies the French-Mauritian J.M.G. Le Clézio's The African (L'africain 2004) and the Ivorian Ahmadou Kourouma's two part work: Allah is Not Obliged (2011) (Allah n'est pas obligé (2000)) and the untranslated and unfinished Quand on refuse on dit non (2004). These pieces share common traits, such as portraits of traumatic historical realities of colonialism and post-colonialism from the perspective of displaced children. Each work examines how children confront and survive a particular form of trauma: the realization that life itself is defined by violence and lies. As such, trauma 
is not an experience outside the realm of the normal. For both Le Clézio and Kourouma, trauma is ontological or the very nature of being itself. And yet for Le Clézio, it is also phenomenological in nature. It is experienced from the subjective position of the body and thus transmitted into conscious awareness. For Kourouma, trauma thrives and is transmitted in language (logos).

In addition to exploring this unique form of trauma (from a non-Western perspective), this research also examines Le Clézio's and Kourouma's models of healing and growth, which include an emphasis on: (a) the body; (b) language; and (c) an empathetic re-encounter with the traumatized self by telling one's “story". Another principle finding is that these texts follow Mutloatse's warning about post-colonial authors kicking, pulling, pushing, and dragging literature into a new form. While these methods of growth might seem kindred to those already developed in the West, they stem from a different cultural perspective defined by a cultural trauma of colonization and an attempt to decolonize the mind from this shared trauma.

\section{Warrant for a decolonization of Trauma Studies}

Before examining these portraits of trauma, the term "trauma" should be defined and a warrant for decolonizing Trauma Studies should be offered. Sociologist and trauma specialist Kai Erikson sees trauma as, "something alien [that] breaks in on you, smashing through whatever barriers your mind has set up as a line of defense" (1995, p. 183). Terms such as "alien", "breaks in on you", "smashing", "barriers" and "a line of defense" are noteworthy, as they evoke a colonization of the mind, including an invasion of culture and a destruction of the natural environment. Since the very concept of trauma is so flexible, Trauma Studies should be well positioned to welcome new models of understanding and treatments from different cultures. Further, the West should be cautious about exporting trauma theories to cultures that have had to develop therapies to survive, as a blatant practice of cultural hegemony could 
lead to serious clinical consequences. In her research on the trauma experienced by villagers during the civil war in Sri Lanka, Alex Argenti-Pillen underscores that Western notions of trauma and healing had the potential to destabilize communities: Western post-trauma coaching disrupted the local methods of healing "terrified hearts", such as cleansing rituals and avoidance of direct speech (2003, p.197). The mere fact that Sri Lankans employ the term "terrified hearts" to refer to what they experienced, while the West went from the terms "shell shock", to "battle fatigue", to "operational exhaustion", to "posttraumatic stress disorder" exposes the wide range of difference in our understanding of trauma. Hence the need to proceed with caution both clinically and theoretically and the reason to explore alternative models of trauma and healing in non-Western trauma novels.

\section{Le Clézio: Surviving the trauma of the violent nature of nature}

Fanon describes how the body keeps the score of racism, colonization, and oppression. "In the colonial world," he writes, "the emotional sensitivity of the native is kept on the surface of the skin like an open sore which flinches from the caustic agent" (1963, p. 19). Fanon's comment propels us to turn to Le Clézio's work, considering that his literary portraits of traumatic experiences and post-traumatic growth center on the body.

In The African, he explores the phenomenological and ontological trauma experienced as a child living in Africa. He describes the "shock" as he grew conscious of the intrinsic violence of nature (2013, loc. 100). For him: "Reality was in the legends. Africa was powerful. For the child I was, violence was all-pervasive, unequivocal" (2013, loc. 144-153). Humans obviously are not spared this "natural" violence, as nature slowly chips away at the human body: "The naked body of that woman... her skin sagging like an empty water pouch, her elongated, flaccid breasts hanging down on her stomach, her dull, cracked, grayish skin, it all seems strange to me, but at the same time true" (2013, loc. 96-98). One 
cannot lie about dying and death in Africa; there is too much immodesty about bodies. The trauma of life is played out in the body and thus as a phenomenological experience. However, this trauma then becomes ontological in nature. The traumatic experience occurs not only as one grows conscious of how intrinsically violent nature is, but also when one realizes that this very nature of being (ontology) is covered up and lied about. In France, for example, the withering effects of old age and dying are hidden in "girdles and petticoats" (2013, loc. 92-103).

It is instructive to consider for a moment the form of Le Clézio's oeuvre in order to capture better these phenomenological and ontological traumatic experiences. First, it should be pointed out that his text follows both an autobiographical and biographical format. It is just as much an exploration of the author's father as a doctor in Africa, as it is about a young man living in Europe and Africa. The narrator appears to need to use both ends of the telescope to view the two continents in order to locate the lies that define each society. He turns to his father who reveals to him the fundamental lies and hypocrisies of European societies that judge people according to their calling cards (2013, loc. 387), while recalling himself the mendacity that prevailed in occupied France during the war (2013, loc. 137). He describes the violent experience of growing conscious of these prevalent and fundamental lies as:

That violence wasn't actually physical. It was muted and hidden like an illness. It was eating away at my body, it gave me irrepressible fits of coughing, such painful migraines that I would hide under the long skirt of the side table, my fists pushed into my eye sockets. (2013, loc. 143) Even though Le Clézio states that this violence wasn't physical, the images and vocabulary of this passage ("eating away at my body"; "irrepressible fits of coughing"; "powerful migraines"; "fists pushed into my eye sockets") suggest that his body was violated and harmed by these lies, which reconfirms our reading of a traumatic experience on both a phenomenological and ontological level. 
Le Clézio finds a source of healing from this trauma at the very source of the trauma itself. He confesses: "I recall a feeling of extreme closeness, of many bodies all around me, a feeling... that ruled out fear. In Africa, the immodesty of bodies was marvellous. It lent perspective, depth, it multiplied sensations, wove a human web around me” (2013, loc. 81). In spite of his initial shock experienced among naked decrepit bodies, the narrator confesses: “And I didn't feel pity, or horror, but rather love and interest, kindled by having glimpsed a truth, a real-life experience" (2013, loc. 99). The mode of healing from this fundamental trauma is kindred to a stimulation of antibodies through vaccine administration. The antigen of trauma is "administered" to the child narrator in a measured and tolerable dose: there is the bodily warmth of other thriving human beings to counteract the sight of decrepit dying bodies before his very eyes.

Despite Africa being "wracked with disease and tribal wars", it was "powerful and exhilarating as well, with its countless children, its dances, the good humour and cheerfulness of the shepherds met along the paths" (2013, loc. 694). A profound sense of bodily human warmth and vitality is also experienced through rituals. The narrator describes the masked theaters, the costumes, the beating drums, the calls, and the dances (2013, loc. 704). Most significantly, these cultural traditions thrived in a "non-colonial Africa" (2013, loc. 696) and were designed as a vital force to counterbalance the overpowering message that the nature of life is intrinsically traumatic. These ritual and theatrical enactments embody emotions and give voice to them; they also give participants the chance to experience with their body a new identity as an emboldened animal or immortal god. They are able to transcend for a moment the vulnerability that otherwise defines human identity.

To drive home the message of the importance of the body in understanding trauma and recovering from traumatic experiences, the narrator invites readers to engage bodily in a literary experience. This is transmitted not so much as an intellectual message, but rather as a phenomenological 
one, for the body's senses are intensely stimulated while reading. The narrator describes, for example, a river of ants moving towards his house, eating and destroying everything it finds: "My mother and father barely had time to gather up their belongings, their clothing, sacks of supplies and medicine. A second later, the dark river was flowing through the cabin" $(2013$, loc. 303$)$. The image of a black river of ants on the move has such power to disturb that the idea of insects invading one's reading space even becomes a reality. This disturbing image brings us physiologically and hence emotionally and physically to a world where others suffered physically and emotionally.

Le Clézio's view that the fundamental nature of life is traumatic and played out in the body as a phenomenological experience and as an understanding of the very nature of being (an ontological understanding) is relevant to Trauma Studies. Psychiatrist Bessel van der Kolk diverts from other Western trauma theorists by confessing: "I discovered that my professional training with its focus on understanding and insight had largely ignored the relevance of the living, breathing body, the foundation of ourselves" (2014, p. 91). While some readers might find it paradoxical to turn to van der Kolk - a Western scientist - to comprehend further trauma recovery, it is important to stress that his research remains "...open to the value of other age-old, non-pharmacological approaches to health that have long been practiced outside Western medicine, ranging from breath exercises (pranayama) and chanting" (2014, p. 88).

Why might the body and bodily exercises play a role in trauma recovery? When describing a traumatic experience, survivors refer to memories imbued with physiological responses. Notably, they struggle to work through both the memory of the traumatic event(s) as well as the post-traumatic experiences reverberating in the body and brain. Van der Kolk encourages thus a therapy focused on the body and internal organs, such as the intestine and the bladder. This method seeks "actually to change 
the patient's physiology, his or her relationship to bodily sensation" through rhythmic practices like drumming and dancing (2014, p. 72).

Secondly, a body-centred therapy is supported by evidence on how language is impaired by traumatic experiences. Research shows that the part of the brain (the Broca region) responsible for producing language goes "offline" when a flashback of a traumatic event is recalled (van der Kolk, 2014, 43). Traumatic experiences also activate the right hemisphere of the brain and deactivate the left (van der Kolk, 2014, p.45). This comprises story telling as well, since "Deactivation of the left hemisphere has a direct impact on the capacity to organize experiences into logical sequences and to translate our shifting feelings and perceptions into words" (van der Kolk, 2014, p. 45). On a related note, “it is enormously difficult to organize one's traumatic experiences into a coherent account—a narrative with a beginning, a middle, and an end" (van der Kolk, 2014, p. 70). In the trauma-provoked condition of dissociation, the thalamus "hibernates" which explains "why trauma is primarily remembered not as a story, a narrative with a beginning, middle, and end, but as isolated sensory imprints: images, sounds, and physical sensations that are accompanied by intense emotions..." (van der Kolk, 2014, p. 70). Even though medical research on the physiological effects of trauma may appear curious in an analysis of a non-Western trauma novel, it does confirm what Le Clézio describes in prose form. Post-traumatic growth methods focused on the body are key to recovery, since trauma originates and continues to dwell in the body. Furthermore, the prevalent Western approach of employing storytelling should be eyed with suspicion. After all, trauma compromises (a) language output and (b) our capacity to think in logical terms and (c) to translate emotions, and thus our ability (d) to string a story together with a beginning, middle and end. There may be other ways to transmit "stories" of traumatic experiences therapeutic in nature. 


\section{Kourouma: Surviving the trauma of communities plagued by violence and lies}

While we have put pressure on the therapeutic effects of stories -- by emphasizing first the importance of engaging the body and secondly the limitations of language for a traumatized mind - this section explores different forms of storytelling revealed in Kourouma's Allah is Not Obliged and his unfinished and untranslated sequel Quand on refuse on dit non (loosely translated as "When We Refuse, We Say No"). Like Le Clézio, Kourouma explores an "ontological trauma” as one realizes just how violent and distrustful human communities are. Kourouma, nevertheless, offers another mechanism of resilience and growth centering not so much on the body or storytelling in a strict sense, but on (a) an experimentation with narrative forms, (b) language, and (c) an establishment of an empathetic link with the former traumatized self.

Kourouma's novels are about a child-soldier Birahima who experiences one traumatic event after another. Destruction and death do not appear in abstract form or as a gradual atrophy of life, but rather as a relentless human drive against everything living, especially the innocent: "You become a childsoldier of course, a small-soldier, a child-soldier so you can have lots to eat and cut some throats yourself; that's all your only option" (2011, loc. 1241-1242). The violence of life is not an exterior drive to be contemplated from afar. It is so prevalent that it torments the mind, as made evident in Birahima's confession: "the innocent people I killed are stalking me, so my whole life and everything round me is fucked" (2011, loc. 99).

Like Le Clézio's narrator, Birahima experiences a type of ontological trauma as he wrestles with the prevalence of lies. He contends: “Education isn’t worth a grandmother's fart anymore, because nowadays even if you get a degree you've got no hope of becoming a nurse or a teacher in some fuckedup French-speaking banana republic" (2011, loc. 60-64). Between the lines is a warning: the belief that hard work in school pays off is a lie, a rude reality all too familiar to disadvantaged students throughout 
the world. He also struggles to make sense of another widespread form of lying. He confesses: “... when I found out that my mother was a devourer of souls, I was so astonished, so sickened, that I cried... for four days. On the morning of the fifth day, I left maman's hut forever..." (2011, loc. 304-307). Birahima believed his mother to be a "devourer of souls" because he lacked a critical spirit that an education might have fostered. He simply accepted the lies others had communicated about her. After years of experience, he later learned to refer to all of that "sorcery, native medicine, magic and a million other extravagant customs" as "bullshit" (2011, 155-157). He calls out the "charlatans" (2011, loc. 1486). He "laughs up his sleeves at all of the bullshit" (2011, loc. 1574). He learns to question the cooked up lies by members of the armies' high command and the "grigriman", his mentor and liar in chief, Yacouba, the Muslim magician and witch doctor (2011, loc. 1339).

Kindred to Le Clézio's text, Birahima's narrative is an attempt to locate not only lies, but also the words to describe the intrinsic traumatic nature of life itself. The traumatic nature of human societies is the norm, thus hinting at the idea that it is even more difficult to become a post-traumatic subject, which contrasts with Western trauma theorists' position. For example, this rude reality goes contrary to Jeffrey Alexander's concept of traumatic states as an "abrupt" harmful event affecting collective identity (2012, p. 14). Alexander argues that, "individual security is anchored in structures of emotional and cultural expectations that provide a sense of security and capability" (2012, p. 14). With these concepts in mind, we can put forward that Birahima experiences trauma as he grows aware not only of the prevalence of violence and lies, but also of the absence of any security, save for Fanta, whom we shall meet shortly.

Seen in this light, Birahima's tale resembles first an "antibuildungsroman" a narrative of personal violation (caused by violence and lies) and destruction and then a buildungsroman , a story about personal development. His "anti-narrative" begins by "violating" language, literary form, and 
typical storytelling: stories with a beginning, middle, and end. The following illustrates just how much his narrative represents a violation destruction of language and storytelling: "The full, final and completely complete title of my bullshit story is: Allah is not obliged to be fair about all the things he does here on earth. Okay. Right. I better start explaining some stuff" $(2011$, loc. 52). The fact that he starts out referring to his narrative as "bullshit" undermines his story. He further undercuts it by relying on enumerations as opposed to prose. (1) He cannot speak French; (2) did not finish much formal schooling; (3) is rude; (4) is only ten years old; (5) has to use four different dictionaries to relate the story of his "fucked up life"; (6) and is cursed, seeing that he mistreated his crippled mother who was thought to be a witch (2011, loc. 55-94). (Birahima's enumerations actually seem to be an attempt to cut through the bullshit and to focus on the very kernel of his problems.) Still, he also casts a shadow of doubt about his narrative enterprise by confessing that he was "fucked-up on lots of hard drugs" (2011, loc. 1914). This confession obviously puts pressure on the veracity of his story.

If we pause to consider what is behind his narrative replete with swear words and enumerations of simple facts, it becomes clear that explanations one through five refer to an idiosyncratic educational background; six hints at a traumatic beginning defining the rest of his life. What is the crux of point six? He admits:

Maman's death makes me sad... Because the accusations that the old kaffir men said were just lies, they were barefaced liars. And I had been a horrible, cruel son to her. I hurt maman, and she died with that hurt in her heart. That's why I'm cursed and the curse goes with me wherever I go! (2011, loc. 376-379)

It is arresting to imagine that this point would add to the bullshit of his story. Birahima seems to be conscious that this was only his first attempt at his life story. He catches himself by stating: "So that's me, and it's not an edifying spectacle. Anyway, now that I've introduced myself, I'm really, truly going 
to tell you the life story of my cursed, fucked-up life" (2011, loc. 105). The enumerated version of his life story does not really seem to count, except that this violated form of storytelling serves as a mirror image of the story of his violated life.

Birahima’s storytelling practices also revolve around experiments with language, as he painstakingly turns to dictionaries to convey his story of trauma: "To make sure I tell you the life story of my fucked-up life in proper French, I've got four different dictionaries, so I don't get confused with big words" (2011, loc. 82-86). By employing dictionaries to avoid confusion about "big words", Birahima appears to be a young mind struggling to make the unknown known. He provides definitions of terms and explanations of concepts that a young person might not understand, thus giving us a sense that he is building his story as he goes along. Or better yet, an encounter with words provokes enlightenment, rather than the other way around. For instance, one senses that he is learning as he writes, "The child-soldiers were really, really angry; they were red in the face they were so angry. (You don't really say 'red in the face' for blacks. Blacks never go red in the face, they just frown.)" (2011, loc. 681-683). It would be no stretch of the imagination to state that dictionaries actually bring his story to life:

I was flicking through the dictionaries that I'd just inherited. Namely, the Larousse and the Petit Robert, the Glossary of French Lexical Particularities in Black Africa and Harrap's. That's when this brilliant idea popped into my calabash (my head) to write down my adventures from A to Z. To recount them with clever French words... (2011, loc. 2819)

And yet, Birahima intertwines the language of standard dictionaries with a visceral one developed in the streets and on the fields, perhaps because the language of dictionaries seems disingenuous. It fails to match the emotional experiences of real life situations. His angered voice seeps out readily: "But I don't 
give two fucks about village customs any more, 'cos I've been in Liberia and killed lots of guys with an AK-47 (we called it a 'kalash') and got fucked-up on kanif and lots of hard drugs" (2011, loc. 77-82). It becomes in fact apparent that Birahima struggles to employ the language of dictionaries:

“That's all I've got to say for today. I'm fed up talking, so I'm going to stop.” (2011, loc. 598-600), and 'I've had enough. I'm fed up telling my life story, with piling up dictionaries. I've had it up to here with everything. Fuck off, the lot of you. I'm shutting up now... Gnamokodé! Faforo! Kourouma, Ahmadou!" (2011, loc. 1675-1677)

These swear words in his native Malinké, the exclamation points, and his telling his readers off obviously point to a profound sense of anger and frustration, and hence his writing appears to serve a cathartic role. Furthermore, passages full of sophisticated words drawn from dictionaries actually resemble a pastiche, as Birahima imitates his oppressors in therapeutic defiance. Is there another way to understand this cathartic experience? Alexander contends that, "catharsis clarifies feeling and emotion by forcing the audience to identify with the story's characters, compelling them to experience their suffering with them and to learn, as often they did not, the true causes of their death" (2012, p. 61). We accompany characters on dark journeys in order to confront our own darkness. What happens, however, if a wiser person accompanies a younger version of him/herself on a traumatic journey of the past? Are there still the same cathartic effects? By writing his story, the more mature Birahima begins to read his younger traumatized self, thus creating an empathetic connection between his traumatized self and the one who writes about his traumatized self. It is this empathy for his younger traumatized self that provides healing. By establishing a sense of safety through a therapeutic alliance between the victim and the nurtured self, by remembering and mourning the traumatic event and by becoming the author of the child's story, the survivor takes care of the traumatized child that no one took care of the first time around. And, if this conclusion seems to contradict van der Kolk's research cited above, then it is 
important to consider that the mature and educated Birahima may have, through his encounter with dictionaries, developed the linguistic tools to tell his story that the young and traumatized Birahima lacked.

This unique form of storytelling — consisting of (a) enumerations to cut through nonsense, (b) swear words to express intense emotions, (c) dictionaries that engender therapeutic pastiches of the oppressors, and (d) therapeutic links between the traumatized self and the survivor — resurfaces in the sequel Quand on refuse on dit non. At the beginning of his second narrative, he embarks once again as a child-soldier to fight in tribal wars, but this time in Ivory Coast. Eventually, Birahima meets Fanta, a well-educated daughter of an Imam, and serves as her bodyguard as she flees north and away from the war. This is when the real bildungsroman begins. Fanta and Birahima establish a type of a therapeutic alliance: they embark on a journey of discovery across the country, sharing stories and meeting other traumatized peoples. Most importantly, Fanta brings Birahima on a voyage of the mind. She teaches him about the country's people, geography, and history. While he confesses that he failed to understand everything she taught him, he carefully recorded the information in his head. Once he had his Baccalaureate, he would write the content of her lessons down. The point is that the learned Fanta mentored him, whereas when he embarked on his first journey, the witchdoctor, Yacouba led him astray. His first journey was sustained and fueled by lies of witchdoctors and warlords. His second by the truth of his country's past.

Birahima serves as a symbol of colonized and post-colonized countries. At first, he embarks on a voyage of independence only to be thrown into tribal wars and duped by one charlatan after another. Eventually, he achieves a degree of independence and freedom when he (a) learns the truth of his country's past dominated by slavery and colonialism and (b) walks through his country where he is comforted by its natural beauty. To give a sense of this transformation that occurs in the sequel, we need 
only refer to these lines: "Nous avons tous les deux marché en silence. C'était merveilleux de se trouver, tous les deux... sur une route éloignée de toute habitation, perdue dans la forêt. J'avais des ailes, j'êtais content comme il n'est pas permis de l'être après le massacre des habitants" (2004, p. 137). (“The two of us walked in silence. It was wonderful for us to be there... on a road far from any other inhabitants, lost in the forest. I had wings, I felt so happy in a way that one shouldn't feel after the massacre of the inhabitants" [my translation].)

Finally, Birahima's story is characterized by a plethora of forms, echoing Mutlatse's comment about dragging literature into a preferred state. His narrative resembles at times a notebook, a diary, an autobiography, and a testament. He writes down words as if he were keeping a vocabulary notebook. As discussed earlier, he turns to writing to record his thoughts for the day, as if keeping a journal. He recollects his life story, kindred to writing an autobiography. And, he paints a landscape of his country and his countrymen, especially marked by colonialism and post-colonial tribal wars, as if he were writing a testament of suffering. Just as Le Clézio creates an autobiography and biography in order to use both ends of the telescope to understand the truth, Birahima uses different forms of intimate literature to cut through the lies that caused his traumatic experiences. The fact that Birahima can experiment with these different forms gives us reason to imagine that he had healed himself by embarking with his mentor Fanta on an adventure in writing that allowed him to empathize with the traumatized child he had been and creatively imagine a new identity exempt from those traumatic experiences.

\section{Concluding remarks}

In her article "Trauma theory and postcolonial literary studies", Irene Vissier argues that current notions in trauma studies (especially Caruth's) center so much on the Freudian concepts of the "unknown" and 
the "unspeakability" that it makes it seem as if narratives defy the experience of trauma (2011). In other words, trauma remains so nebulous that narratives do not lend themselves to the experiences of trauma. However, narratives are not transmitted in the same way in all cultures, and hence it is naïve to assume that all stories defy the experience of trauma. This research on Le Clézio's and Kourouma's work provides evidence of the therapeutic effects of narratives to treat traumatic experiences that are ontological and phenomenological in nature and perpetrated through language. In the Western world, human vulnerability and dying are masked by cosmetics, lies, and hypocritical costumes. In Africa, superstition, magic, and witchdoctors explain them away. In both cases, language plays a fundamental role in the traumatic experience of the ontological lie. Thus, language needs to play a fundamental role in the healing process. In the case of Kourouma's work, language is harnessed, so that the narrator can establish a bond of empathy with the child he once was just as a mentor establishes a bond with his pupil. In Le Clézio's narrative, both the body and a flexible form of writing, which provide multiple perspective are involved in healing.

Contrary to these findings, Western Trauma Studies have a tendency to argue that trauma compromises collectivism. Erikson has put forward that what used to be called "therapeutic communities" should be called "corrosive communities" (1995, p. 189). He explains that disasters seem to provoke divisions among communities, leading people to split into factions of those who have been touched directly by the toxic event and those who have not. Be that as it may, Erikson seems almost to undermine his own research by pointing out that backstories accompany disasters caused by humans or, more euphemistically, by technology. He writes: "Technological disasters... being of human manufacture, are at least in principle preventable, so there is always a story to be told about them, always a moral to be drawn from them" (1995, p.191). His use of passive vocabulary is quite curious, as it conveys a sense that computer programs generate stories and draw morals. Traumatized peoples tell 
stories and draw morals, and they do so within communities, just as Le Clézio did with his father's help and Birahima with Fanta's. In light of this distinction, one can draw the conclusion that traumatic events caused by other humans (as opposed to "acts of god") actually provoke a sense of community cohesion through narrative acts. This research on Le Clézio's and Kourouma’s work obviously shows the therapeutic contributions of communities. Besides, to draw a sweeping conclusion about how people react to trauma seems foolhardy, simply because cultural differences prevail in "normal" conditions.

Finally, establishing a sense of safety through a therapeutic alliance between the nurtured self and the victim, mourning and remembering the traumatic event, and becoming the author of one's own story may be therapeutic to some. Remaining true to one's "unknown" story, engaging in a cathartic journey with another may lead to recovery. Priming the body by engaging in singing and theatrical exercises before telling one's story is essential for restoring the body. These findings indicate that a wide range of therapies from the literary arts and imagination is essential for post-traumatic growth. Still, what other forms of treatments, especially from non-Western communities, can inspire our therapies? It may very well be that to develop new therapies, we first need to observe carefully and locate new forms of trauma, just as in this research we focused on the trauma that was ontological and phenomenological in nature. Other topics to study more thoroughly are traumas associated with environmental degradation__ as exposed in Vandana Shiva's research (2010). The notion that there are forms of trauma to discover and therapies to develop in unexpected places echoes Olivier Sachs's position: "The exploration of deeply altered selves and worlds is not one that can be fully made in a consulting room or office" (1995, p. xix).

\section{References}

Alexander, J.C. (2012). Trauma: A Social Theory, Malden, MA: Polity Press. Argenti-Pillen, A. (2003). Masking Terror: How Women Contain Violence in Southern Sri Lanka, 
Philadelphia, PA: University of Pennsylvania Press.

Caruth, C. (1995) (Ed.). Trauma: Explorations in Memory, Baltimore, MD: Johns Hopkins Univ. Press.

Craps, Stef. (2013). Postcolonial Witnessing: Trauma out of Bounds, London: Palgrave Macmillan.

Craps, S. \& Buelens, G. (2008). Introduction: Postcolonial Trauma Novels, Studies in the Novel, Vol. 40, numbers $1 \& 2$ (Spring \& Summer 2008), 1-22.

Deleuze, G. (1999). Critique et Clinique. Paris: Les Editions de Minuit, 1993.

Eagleton, T. (2003). After Theory, New York, NY: Basic Books.

Fanon, F. (2004). The Wretched of the Earth, (R. Philcox, Trans.), New York: NY, Grove Press.

Erickson, K. (1995). “Notes on trauma and community.” In Trauma: Explorations in Memory, edited by Cathy Caruth, 183-199. Baltimore, MD: John Hopkins Univ. Press.

Herman, J. L. (2015). Trauma and Recovery: The Aftermath of Violence-From Domestic Abuse to Political Terror, New York, NY: Basic Books.

Kleinman, A. (1988). The Illness Narratives: Suffering, Healing, and the Human Condition, New York, NY: Basic Books.

Krystal, H. (1995). “Trauma and Aging: A Thirty-Year Follow-up.” In Trauma: Explorations in Memory, edited by Cathy Caruth, 76-99. Baltimore, MD: John Hopkins Univ. Press.

Kourouma, A. (2004). Quand on refuse on dit non. Paris: Editions du Seuil.

Kourouma, A. (2007). Allah is Not Obliged, (F. Wynne, Trans.), New York, NY: Anchor Books. Kindle edition.

LaCapra, D. (2014). Writing History, Writing Trauma. Baltimore, MD: Johns Hopkins Univ. Press.

Luckhurst, R. (2013). The Trauma Question. New York, NY: Routledge Press.

LeClézio, J.M.G. (2013). The African, (C. Dickson, Trans.), Jaffrey, New Hampshire: David Godine 
Publishers. Kindle edition.

Mengel, E. \& Borzaga, M. (Eds.). (2012). Trauma, Memory, and Narrative in the Contemporary South Africa Novel, New York, NY: Rodopi Press.

Mutloatse, M. (Ed.). (1981). Forced Landing: Africa South: Contemporary Writings, Johannesburg, South Africa: Ravan Press.

Rothberg, M. (2008). Decolonizing trauma studies: A response, Studies in the Novel, Vol. 40, nums. $1 \& 2$ (Spring \& Summer 2008). 224-234.

Sachs, O. (1995). An Anthropologist on Mars: Seven Paradoxical Tales, New York, NY: First Vintage Books.

Shiva, V. (2010). Staying Alive: Women, Ecology, and Development, New York, NY: South End Press. Van der Kolk, B. (2015). The Body Keeps the Score: Brain, Mind, and Body in the Healing of Trauma, New York, NY: Penguin Random House.

Vissier, I. (2011). Trauma theory and postcolonial literary studies. Journal of Postcolonial Writing Volume 47, Issue 3. Retrieved from http://www.tandfonline.com/doi/abs/10.1080/17449855.2011.569378 